Bond University

Research Repository

\title{
Assessing differences in anthropometric and fitness characteristics between police academy cadets and incumbent officers
}

Orr, Rob Marc; Dawes, James Jay; Pope, Rodney R; Terry, Joseph

Published in:

Journal of Strength and Conditioning Research

DOI:

10.1519/JSC.0000000000002328

Licence:

Other

Link to output in Bond University research repository.

Recommended citation(APA):

Orr, R. M., Dawes, J. J., Pope, R. R., \& Terry, J. (2018). Assessing differences in anthropometric and fitness characteristics between police academy cadets and incumbent officers. Journal of Strength and Conditioning Research, 32(9), 2632-2641. https://doi.org/10.1519/JSC.0000000000002328

\section{General rights}

Copyright and moral rights for the publications made accessible in the public portal are retained by the authors and/or other copyright owners and it is a condition of accessing publications that users recognise and abide by the legal requirements associated with these rights.

For more information, or if you believe that this document breaches copyright, please contact the Bond University research repository coordinator. 
Assessing differences in anthropometric and fitness characteristics between police academy cadets and incumbent officers

Brief Running Head: Fitness differences between police cadets and officers

Laboratory where the research was conducted: Tactical Research Unit, Bond University

Robin Orr ${ }^{1}$, J. Jay Dawes ${ }^{1,2}$, Rodney Pope ${ }^{1}$, Joseph Terry ${ }^{3}$

${ }^{1}$ Tactical Research Unit, Bond University, Gold Coast, QLD, Australia, 4216

${ }^{2}$ Department of Health Science, University of Colorado: Colorado Springs, Colorado, United

States of America

${ }^{3}$ Faculty of Health Sciences and Medicine, Bond University, Gold Coast, QLD, Australia, 4216

Dr Robin M. Orr (PhD) - Corresponding Author

Tactical Research Unit,

Bond University

Robina, Queensland, QLD, Australia, 4216

Email: rorr@bond.edu.au 
Dr. J. Jay Dawes (PhD)

Department of Health Sciences

University of Colorado-Colorado Springs

Colorado Springs, CO.

Email: jdawes@uccs.edu

Dr Rodney Pope (PhD)

Tactical Research Unit,

Bond University

Robina, Queensland, QLD, Australia, 4216

Email: rpope@bond.edu.au

\section{Mr Joseph Terry (DPHTY)}

Faculty of Health Sciences and Medicine

Bond University, Gold Coast, QLD, Australia, 4216

Email: jterry@student.bond.edu.au 
Fitness differences between police cadets and officers 1

\section{ABSTRACT}

The physical fitness of police officers must be developed in new cadets and sustained in incumbent officers. The aims of this study were to profile and compare the anthropometric and fitness characteristics of police academy cadets and incumbent officers of varying ages from a single police force. Retrospective data for 84 police academy cadets $(\hat{\delta}=66$, mean age $=27.96 \pm 5.73 \mathrm{yrs} ; \uparrow=18$, mean age $=30.50 \pm 5.76 \mathrm{yrs})$ and 80 incumbent police officers $(\hat{\sigma}=73$, mean age $=39.43 \pm 8.28$ yrs; $q=7$, mean age $=37.86 \pm 3.67$ yrs) were compiled. Data included participant age, anthropometric (weight, lean mass and fat mass) and fitness measurements (1minute push-up, 1-minute sit-up, 1RM bench press, vertical jump, 300-meter and 1.5-mile run). Male cadets exhibited significantly lower fat mass than male officers (12.4 vs $15.1 \mathrm{~kg}, \mathrm{p}=.003)$. These differences were fully explained by the age differences between these groups $(p=.046)$. Male cadets were more aerobically fit with greater muscular endurance than male officers ( $p<.001$ for all measures). This difference was not explained by age differences ( $p>.80$ for all measures). Male cadets also exhibited higher anaerobic fitness than male officers $(p<.001)$.Age differences only partially explained this difference $(\mathrm{p}=.01)$. Female cadets exhibited greater upper body strength and muscular endurance than female officers ( $p<.004$ for all measures), independent of age. Being a police officer, rather than age progression, may largely account for observed lower levels of fitness in incumbent officers when compared to cadets. Formalized physical training programs for incumbent police officers are needed if their fitness is to be maintained and risk of cardiovascular disease minimized.

Keywords: law enforcement, police officer, recruits, aging, workplace 
Fitness differences between police cadets and officers 2

\section{INTRODUCTION}

The law enforcement population must perform a wide range of job tasks (35). These job tasks range between those that are relatively sedentary in nature and those that are extremely physically demanding, involving running, pulling, pushing, lifting, and carrying $(4,6,26,27)$. Research supports the supposition that physical fitness is strongly associated with the ability of this population to perform their critical job tasks $(6-8,38)$. As such, to perform these tasks safely and efficiently, officers in this population must possess a certain level of fitness in several categories, including muscular power, strength and endurance, and cardiovascular endurance (6$8,26,27)$.

To become police officers, new cadets must undergo training, where they are conditioned to prepare them for the rigors of their new occupation $(31,33)$. The importance of this requirement is highlighted by many law enforcement agencies requiring cadets to demonstrate sufficient levels of fitness to be accepted into their field (3). What is not well known is whether new cadets obtain levels of fitness that are commensurate with those of the incumbent officer population. One difficulty in examining whether fitness gained during cadet training meets that of incumbent officers is the potential variability in the fitness of the incumbent officer population. Specifically, consideration needs to be given as to whether the incumbent (a fully qualified and sworn) police officer population loses fitness as they get older or due to the sedentary elements of their occupation. 
Fitness differences between police cadets and officers 3

In a longitudinal study by Sorensen et al.,(38) researchers found that Finnish Law Enforcement Officers (LEO) significantly decreased in muscular strength (pull-up) and endurance (push-up and sit-up) and cardiovascular endurance over a 15-year period. In contrast, a longitudinal study by Boyce et al., (7) found that there were significant improvements in strength (bench press) levels among LEO from their initial recruitment to in-service testing conducted 12.5 years later. Also, in contrast to a study by Sorensen et al.,(38) observing a significant decrease in muscular endurance across the age range, a study by Dawes et al., (12) observed that LEO generally maintained their push-up ability. It should be noted that the study by Dawes et al., was a crosssectional study rather than a longitudinal study, although their LEO sample size was two to five times larger than the sample sizes used in the aforementioned studies. Given these results, the available research appears to be inconclusive as to whether fitness, as defined by the components measured, decreases, increases or does not change over the duration of an officer's career.

There is no known research specifically investigating whether academy cadets are at a fitness level commensurate with the incumbent officer population nor whether fitness levels in cadets may be associated with age. Research investigating whether fitness levels in the incumbent officer may be associated with age is currently scarce $(12,13,29)$, with the few available studies inconclusive with some research finding no significant differences between age groups (12) and other research finding differences between some age group categories but not others (29). While it might be assumed that the cadet population is younger and fitter than the incumbent officer population and that mean age differences between these population might then explain any mean fitness differences between these populations, these possibilities are yet to be comprehensively assessed. Therefore, the aims of this study were to profile and compare the anthropometric and 
fitness characteristics of police academy cadets and incumbent officers of varying ages from a single police force.

\section{METHODS}

\section{Experimental Approach to the Problem}

Retrospective data from a U.S. state law enforcement agency were provided. The data included samples from both male and female cadets and incumbent officers. In addition to body weight and body composition measures (sum of skinfolds), baseline data collected as part of departmental processes were provided for lower body power (Vertical jump [VJ]), upper body strength (1 Repetition Maximum [RM] Bench Press), upper body and trunk muscular endurance (1-minute push-ups and 1-minute sit ups), anaerobic performance (300 m run) and aerobic performance (1.5-mile run). Statistical analysis between genders (male and female) and occupational status (cadet versus incumbent officer) were performed to investigate potential differences between these groups.

\section{Subjects}

The study cohort was comprised of 84 police academy cadets (mean age $=28.50 \pm 5.80 \mathrm{yrs}$ ) included 66 male cadets (mean age $=27.96 \pm 5.73 \mathrm{yrs}$; mean weight $=85.65 \pm 11.92 \mathrm{~kg}$ ) and 18 female cadets (mean age $=30.50 \pm 5.76 \mathrm{yrs}$; mean weight $=62.96 \pm 11.04 \mathrm{~kg}$ ). The 80 incumbent officers (mean age $=39.31 \pm 7.93 \mathrm{yrs}$ ) included 73 male officers (mean age $=39.43 \pm$ $8.28 \mathrm{yrs} ;$ mean weight $=87.47 \pm 11.59 \mathrm{~kg})$ and 7 female officers $($ mean age $=37.86 \pm 3.67 \mathrm{yrs}$; 
Fitness differences between police cadets and officers 5

mean weight $=63.38 \pm 5.16 \mathrm{~kg}$ ) from a law enforcement agency who participated in a voluntary physical fitness program. Ethics approval was obtained from the University of Colorado, Colorado Springs Institutional Review Board for human subjects (IRB 15-074) and the Bond University Human Research Ethics Committee (RO1927). Following ethics approval, data for this retrospective cohort study were obtained in non-identifiable form from the custodians of the relevant personnel records from a single U.S. state law enforcement agency.

\section{Procedures}

When the data were first gathered for the cohort considered in this study, the U.S. state law enforcement agency's training facility was utilized for the conduct of all anthropometric measurements (weight and 3-site skin-fold) and for the assessment of muscular power (vertical jump), strength (1 RM bench press) and endurance (push-ups and sit-ups). Following these measurements, participants then completed the anaerobic (300-meter sprint) and aerobic (1.5 mile run) fitness measurements on a predetermined course within the local area. For the academy cadets these measures were captured following a 6-month training program. Further specifics on each of the measurements are provided below. All testing sessions were conducted by the agency's training staff between $7 \mathrm{am}$ and noon. Each instructor responsible for conducting these assessments was certified by either the National Strength and Conditioning Association (i.e., Certified strength and Conditioning Specialist) or by the Cooper Institute (i.e, Law Enforcement Fitness Specialist). Each test was performed based on the standards outlined by the Cooper Institute (11) and Hoffman and Collingwood (23). All officer data analyzed in this study was collected in the same month, within a two-week time frame in July, 2013. The cadet scores analyzed in this study consisted of aggregated test data from the last fitness test conducted for 
Fitness differences between police cadets and officers 6

four training academy classes in July between the years 2010-2013. Since this data was not originally collected for research purposes, exercise, hydration and nutritional status were not controlled. To minimize the effects of fatigue, all power and strength tests were performed prior to those that required a greater emphasis on anaerobic/aerobic endurance. All tests were administered within 5-10 minutes of one another in the following order.

Weight: Initially recorded in pounds (lb), participants' body weights were measured using a doctor's beam scale (Cardinal; Detecto Scale Co, Webb City, MO), and were later entered into a spreadsheet, where they were converted to kilograms $(\mathrm{kg})$.

Skin-fold Measurements: Body composition was determined using skin-fold measurements based on the methods described by Jackson and Pollock (25). The three sites used for the skinfold measurements were the chest, abdomen and thigh for male participants and the triceps, suprailium and thigh for female participants. All measures were taken on the right side of the body using Lange Skinfold Calipers (Lange, Beta Technology Inc, Cambridge, MD). Participants' body fat percentage (\%BF), lean body mass (LBM $[\mathrm{kg}])$ and fat mass (FM $[\mathrm{kg}])$ were then calculated by entering their skin-fold measurements and body weights into the prediction formulae described by Jackson and Pollock (25). This method was selected over other skinfold assessment methods which utilize additional skinfold sites due to organizational time constraints. 
Fitness differences between police cadets and officers 7

Vertical Jump: Participant lower body muscular power was determined using the vertical jump test and the scores were measured with the Vertec ${ }^{\mathrm{TM}}$ apparatus (Vertec Scientific Ltd., Aldermaston, UK). Before beginning, all participants performed a 3-5-minute self-selected warm-up. No familiarization tests were conducted for this assessment as all participants had conducted this test previously as part of their yearly fitness assessment or academy entrance standard. Each participant's standing reach heights was then measured. Each participant was then instructed to execute a countermovement jump with an arm-swing in order to reach the highest level they could on the device. All participants were allowed no less than 10 sec. and up to $30 \mathrm{sec}$. rest between each jump. The participants VJ height was determined by subtracting standing reach height from jump height. Participants were given three attempts and the greatest height achieved (rounded to the nearest 0.5 inch) was used as their final score. This result was then converted to $\mathrm{cm}$.

1 RM Bench Press: Upper body strength was measured using a 1-repetition maximum effort bench press test with the participants lying down on a standard flat bench press bench with their eyes lined up below the barbell. During this test, participants were required to maintain 5-points of contact (head, shoulders and glutes in contact with the bench and both feet on the floor) for the entirety of the movement. To begin, participants lifted the barbell off the rack and positioned it directly over their chest. From this position they then lowered the bar down until the bar lightly touched their chest and then proceeded to press the bar back up until their elbows reached full extension. Officers and cadets were instructed to select a load that would allow them to achieve the $1 \mathrm{RM}$ in fewer than five attempts. A minimum of 5 minutes rest was required between each trial. If a participant was unable to achieve a lift they were afforded the opportunity to lower the 
Fitness differences between police cadets and officers 8

weight. Instructors provided both officers and cadets guidance regarding weight selection to ensure that the $1 \mathrm{RM}$ was determined within these parameters. The final maximum load lifted for a single repetition with correct technique was recorded in $\mathrm{kg}$.

1-Minute Push-Ups: Participants began the push-up test in the 'up' position, which required their body to be in a rigid and straight position, their elbows in full extension, their hands placed slightly wider than their shoulders and their fingers pointed forward. Partners then placed a closed fist on the floor underneath the participant's chest for a consistent measurement of pushup depth. When instructed to begin, each participant was required to lower themselves, touching their chest to the partner's fist and then returning to the 'up' position by extending their elbows. Each participant repeated this movement as many times as possible within the allotted time of 1minute. Time was kept with a stopwatch by the tester and the number of repetitions performed were recorded by each participant's partner. Rest was allowed in the 'up' position, but the participant was required to maintain a straight and rigid alignment with the legs and torso. The test was completed if the participant was unable to maintain the required movement form, or once the 1-minute time frame had ended.

1-Minute Sit-Ups: The other muscular endurance test was the 1-minute sit-up test, as described by Hoffman and Collingwood (24). For this test, participants were to begin lying in a supine position with knees bent to 90 degrees, feet flat on the floor and hands placed behind the neck with fingers linked together. The participant's feet were secured to the ground by their partner. Once instructed to begin, each participant flexed their trunk and touched their elbows to their knees by lifting their shoulders off the ground. This movement was repeated as many times as 
Fitness differences between police cadets and officers 9

the participants could achieve within the allotted time of 1-minute. As with the push-up test, time was kept on a stopwatch by the tester while the partner counted and recorded each participant's number of repetitions.

300-Meter Run. Anaerobic performance was tested using a 300-meter sprint test performed on a course measured around a city block. The test involved the officers running the 300 -meter course as fast as possible, with their final times being recorded on a stopwatch and rounded to the nearest $0.10 \mathrm{sec}$.

1.5-Mile Run. Aerobic performance was measured using a 1.5-mile run. Using a 3/4 mile course measured around a local city block, officers were instructed to complete two laps as fast as they could, with their times being recorded to the nearest $0.10 \mathrm{sec}$ using a stopwatch. Prior to beginning the test, a two-hour rest period was provided for the participants to allow for an appropriate recovery period following the previous tests.

\section{Statistical Analysis}

The extracted data was entered into a Microsoft Excel spreadsheet before being imported into the Statistical Package for the Social Sciences (SPSS) version 22 for statistical analysis. Descriptive statistics were generated, by gender and by cadet and officer groups, including means and standard deviations (SD) of participant age, anthropometric measurements (weight, body fat percentage, lean mass and fat mass) and fitness scores (vertical jump, bench press, push-ups, situps, 300-meter sprint and 1.5-mile run). Independent samples t-tests were then used to examine, 
Fitness differences between police cadets and officers 10

for each gender separately, differences between the mean anthropometric and fitness results of police academy cadets and incumbent officers. Given the potential for mean age differences between police cadets and incumbent officers to impact on the comparisons of these groups, differences between the two groups in anthropometric and fitness results were further analyzed using an Analysis of Covariance (ANCOVA), with age set as a covariate, so that the relative contributions of age and group in accounting for the variance in the anthropometric and fitness results could be assessed. Only male personnel were included in the ANCOVA, since numbers of female personnel were too few to allow for valid ANCOVA. Each of the male cadet and officer groups was also sub-divided into 5-year age brackets, in order to clarify the range of ages represented in each group and enable plotting and visual depiction, with smoothed curves, of the differences in anthropometric and fitness results identified in the ANCOVA, by age bracket and group. Age brackets in either group which contained less than five personnel were removed from the resulting plots, to ensure the estimates of results for each age bracket depicted in the plots were valid, being each based on data from at least 5 personnel. A priori power analyses conducted using $\mathrm{G}^{*}$ Power software (version 3.1.9.2, 2014) indicated that these participant numbers would yield a statistical power of 0.89 to detect a medium effect size (Cohen's $\mathrm{f}=.25$, alpha $=0.05)$ in the ANCOVA to be conducted to assess group differences while controlling for a single covariate (age). The overall level of significance for statistical tests was set at $0.05, a$ priori. 
Fitness differences between police cadets and officers 11

\section{RESULTS}

As anticipated there was a significant difference in mean age between the cadet and officer groups (Table 1). Male cadets were on average significantly younger than male officers (cadet mean age $=27.95 \pm 5.73$ yrs, officer mean age $=39.43 \pm 8.28 \mathrm{yrs} ; \mathrm{t}(126.78)=9.531, \mathrm{p}<.001$, unequal variances). Likewise, female cadets were on average significantly younger than female officers (cadet mean age $=30.50 \pm 5.76$ yrs, officer mean age $=37.86 \pm 3.67 \mathrm{yrs} ; \mathrm{t}(17.38)=3.789, \mathrm{p}=0.001$, unequal variances).

Insert Table 1 here

When comparing male cadets to male officers, there were no significant differences between groups in VJ (t[136] $=0.163, \mathrm{p}=.871)$ results or $1 \mathrm{RM}$ Bench Press $(\mathrm{t}[136]=0.809, \mathrm{p}=.420)$. However, the male cadets had a significantly lower mean FM $(\mathrm{t}[135]=3.036, \mathrm{p}=0.003)$ and significantly higher mean push-up score $(\mathrm{t}[130.83]=5.083, \mathrm{p}<0.001$, unequal variances $)$ and situp score $(\mathrm{t}[136]=6.155, \mathrm{p}<0.001)$ (Table 1$)$. The male cadets also ran significantly faster in 300 $\mathrm{m}$ runs $(\mathrm{t}[136]=6.075, \mathrm{p}<0.001)$ and 1.5 mile runs $(\mathrm{t}[136]=5.240, \mathrm{p}<0.001)$. However, after adjustment for age as a covariate in the planned ANCOVA, no statistically significant difference in FM levels remained between male cadet and officer groups $(F[1,134]=1.201, p=0.275)$; rather, the observed between-group differences in FM (Table 1) were explained by differences in the age profiles of the groups, with age being a significant predictor of FM in these male personnel $(\mathrm{F}[1,134]=4.052, \mathrm{p}=0.046)(\mathrm{Fig} 1)$. 
Fitness differences between police cadets and officers 12

Fig 1. Fat mass, by age bracket and group

Conversely, the significantly higher mean push-up and sit-up results and significantly faster mean 1.5 mi run time observed in the male cadets when compared to male officers (Table 1) were not explained by differences between these groups in age profiles; age was not a significant predictor of results in these fitness tests (push-ups $\mathrm{F}[1,135]=0.656, \mathrm{p}=0.419$; sit-ups $\mathrm{F}[1,135]=2.576, \mathrm{p}=0.111 ; 1.5 \mathrm{mi}$ run $\mathrm{F}[1,135]=3.101, \mathrm{p}=0.81)$ when included as a covariate in the ANCOVA (Figs 2 - 4).

Fig 2. Push-up results, by age bracket and group

Fig 3. Sit-up results, by age bracket and group

Fig 4. 1.5 mile run times, by age bracket and group

For the 300-m anaerobic run test, both age $(F[1,135]=6.245, \mathrm{p}=0.014)$ and group

$(\mathrm{F}[1,135]=10.605, \mathrm{p}=0.001)$ were significantly associated with test results for male personnel, with both being a cadet and being younger associated with superior performance in this test (Fig 5). After adjustment for age, male cadets exhibited a marginal mean 300-m run time (estimated for age 33.94 years $)$ of $49.67( \pm 1.04)$ secs and male officers a slower mean time of 54.88 $( \pm 0.986)$ secs (estimated for the same age). 
Fitness differences between police cadets and officers 13

Fig $5.300 \mathrm{~m}$ run times, by age bracket and group

Female cadets were able to perform a significantly heavier $1 \mathrm{RM}$ bench press $(\mathrm{t}[21.39]=2.965$, $\mathrm{p}<0.001$, unequal variances) and significantly more push-ups $(\mathrm{t}[23]=3.153, \mathrm{p}=0.004)$ than female officers. For both of these measures, the significant differences were found to be independent of age $(1 \mathrm{RM}$ bench press $\mathrm{F}[1,22]=0.879, \mathrm{p}=0.359$; push-ups $\mathrm{F}[1,22]=0.240, \mathrm{p}=0.629)$.

\section{DISCUSSION}

The aims of this study were to profile and compare the anthropometric and fitness characteristics of police academy cadets and incumbent officers of varying ages from a single police force. The anthropometric and fitness profiles of the study populations are presented in Table 1, by gender and by group (police academy cadet or incumbent officer). Figs 1 - 5 provide additional information regarding the ways in which anthropometric and fitness attributes of male personnel varied between cadet and officer groups and with age, where they did indeed vary. Of note, the results indicate that, on average, the male cadet population exhibited significantly higher levels of aerobic fitness and upper body endurance and strength than male incumbent officer population and that these differences between populations could not be explained by differences in age profiles between these two populations (Figs 2 - 4). Rather, the occupation of the populations (as cadets in training or incumbent officers) was the key associated factor. In contrast, while the male cadet population typically exhibited lower levels of FM than male incumbent officer population, this difference between populations in FM could be entirely explained by the positive correlation between FM and age; once adjustments were made for age, it became evident that 
male cadets and officers of the same age exhibited similar levels of FM (Fig 1). Interestingly, anaerobic running performance in these male populations were associated with both age and group, with both cadet status and younger age being independently associated with better scores on the 300m anaerobic run test (Fig 5). However, with respect to body weight, lean mass, vertical jump height and 1RM bench press performance, the male cadet population and male officer population were similar. Among the female population, for whom lower numbers prohibited some of the more detailed analyses that were possible for male population, it was evident that the female cadet population performed significantly better in muscular strength (1 RM bench press) and muscular endurance (push-ups) than female officer population, but on most other measures the female populations were similar.

The FM levels measured in incumbent officers and police academy cadets in this study are similar to those reported in other studies. For incumbent police officers, a previous study of one cohort of 76 male police officers reported a mean FM of $14.24 \mathrm{~kg}$ (14) and this was lower than the mean FM reported for another cohort of 327 police officers (mean FM=18.70 kg) (7), with the FM observed among officers in the current study falling between these FM levels. A study by Cocke et al., (10), investigating the impact of two different training programs on a group of police cadets, found that at the commencement of the program the cadets' mean FM was 15.96 and $15.70 \mathrm{~kg}$ for each group, respectively. However, following their initial cadet training, FM reduced to 12.71 and $12.04 \mathrm{~kg}$, respectively. These final FM results by Cocke, et al., (10) are similar to the FM measured in cadets in the current study $(q=12.43 \mathrm{~kg}$ and $\widehat{\delta}=13.39 \mathrm{~kg})$. The finding of the current study that FM was positively correlated with age is supported by the study of Boyce et al., (7) which followed 327 police officers (30 women and 297 men) over 
approximately 12.5 years from initial recruitment through to in-service positions. The study found that both the male and female officers gained in FM (male FM pre $=12.2 \mathrm{~kg}$ : male post $=$ $18.7 \mathrm{~kg}$ : female pre $=12.0 \mathrm{~kg}$ : female post $=187.0 \mathrm{~kg}$ ) over their service period, as their age increased.

The results of this study suggest that occupational status of a police population (cadet in training or incumbent officer), rather than age, may be a key contributing factor towards the reduced muscular endurance observed in a police officer population when compared to a cadet population. This finding is supported by the work of Dawes et al., (12) who found that age had no significant impact on push-up performance among an incumbent police officer population. Taken together, the results of these studies suggest that the incumbent officer population reported in this study, in general, may have a lower level of muscular endurance, on average, than police academy cadets due to their environment rather than due to their typically higher age. This supposition is supported by Fig 2, which depicts the significant difference in push-up performance observed between the cadet and officer populations while performance changed little in either group as age increased. Similar results were observed in the sit-up test (Fig 3) and $1.5 \mathrm{mi}$ run (Fig 4), indicating that the muscular endurance and cardiovascular fitness possessed by police personnel are more closely associated with the population to which they belong, whether police cadets or incumbent police officers, rather than with their age.

A potential factor contributing to lower levels of muscular endurance and cardiovascular endurance seen in the incumbent officer population when compared to the cadet population is the significantly lower amount of work-related physical activity performed by officers, which has 
Fitness differences between police cadets and officers 16

been highlighted by numerous studies investigating patterns of police physical activity $(6,26$, 27). Despite the sporadic requirement for an officer to perform rigorous and unpredictable physical work tasks, most of an officer's workday can involve relatively sedentary activity, for example driving or completing desk work and reports $(2,6)$. With cadets participating in a training program that provides designated weekly physical training sessions, their physical activity tends to be more intense and more goal-orientated than that of an incumbent officers (31). Likewise, cadet training environments are known to often be more physically demanding than the workplace for tactical personnel, as cadets have a limited period of time in which to develop the required attributes of their profession (32). In addition, cadets and new tactical trainees are required to pass fitness assessments prior to graduation and, as assessments drive learning (and hence training), cadets undertake physical training to prepare for these assessments. These assessment requirements may not exist for incumbent law enforcement officers who are no longer required to pass fitness standards once they leave their cadet training (5).

Apart from a potential lack of ongoing fitness standard requirements, other potential contributors to lower levels of physical activity in the incumbent officer population when compared to the cadet population include shift work, unpredictability of daily tasks and chronic back pain. Shift work, which is common in the law enforcement population, can see officers work a series of shifts ( 2 x 12 hr day shifts, followed by $2 \times 12$ hr night shifts) before being rostered for a few days off (23). While this shift work can affect the body's natural circadian rhythm (1), lead to an increased risk of long-term injury (39), and impact on sleep quality (17), of most relevance to the findings of this study is the negative impact on the desire to conduct physical activity (21). As 
such, the shift work demands of this incumbent law enforcement population may have impacted on the physical fitness of the incumbent officer population in this study to a greater extent than the fitness of the cadets in training who were not exposed to a shift work cycle.

Given the unpredictable nature of their occupation, law enforcement officers may be less inclined to perform physical exercise at the commencement of, or during, their shift given that they may suddenly be required to perform efforts of near maximal exertion in a life threatening situation (23). For example, a training session that induces upper body muscle fatigue could negatively impact on the explosive strength needed to subdue an offender and subsequently place their lives and those of the general public at risk.

Finally, with the lower back being a leading bodily site of injury in this population $(20,37)$ the relatively high incidence of lower back pain in this population is not surprising. While commensurate with the prevalence levels found in the general population, a study looking at reported lower back pain in a police officer population found that only $8.5 \%$ of the $54.9 \%$ of officers who reported chronic lower back pain had this pain prior to joining the force (9). Thus, it can be considered that the cadet population would have a notably lower prevalence of lower back pain than the incumbent population. This premise is supported by a study in another police population that found that the movement capabilities of attested officers were significantly poorer in trunk rotational stability than those of a cadet population and may predispose them to a high risk of injury (34). While evidence is conflicting over whether chronic lower back pain is (28) or is not (19) associated with decreased physical activity, the higher prevalence in the 
incumbent law enforcement population may have contributed to their lower levels of fitness when compared to the cadet population.

The downstream effect of this lower level of physical activity, whether it be due to reduced requirements to be physical active, shift work, the unpredictability of their daily tasks or chronic back pain, can be seen in higher levels of obesity and higher Body Mass Index (BMI) in the law enforcement population (38) when compared to the general population. In addition, physical inactivity and having lower levels of cardiovascular fitness are associated with an increased risk of cardiovascular disease (CVD) $(15,16)$ with research suggesting that there is a higher incidence of such diseases in law enforcement officers when compared to the general population $(36,40)$. The stresses involved with law enforcement work have been shown to be one of the direct risk factors in the development of CVD in officers $(16,18)$ as well as having an impact on the development of other CVD risk factors (18). In an attempt to address the issue of workrelated stress in tactical populations, Duarte et al.(16) investigated the impact that cardiovascular fitness has on physiological responses to stress in army personnel. Their findings indicated that individuals with better cardiovascular fitness tended to present with less stress-related physiological patterns than those who were not as fit. With the results of this current study indicating that incumbent police officer population has a lower cardiovascular fitness level than a cadet population, it can be recognized that incumbent officers may have the tendency to increase FM and lose cardiovascular aerobic fitness during their career as an officer, and this hypothesis warrants further research. Regardless, the results of the current study indicate that incumbent officers do currently have a lower level of cardiovascular fitness than cadets of similar ages (Fig 4). 
Fitness differences between police cadets and officers 19

When paired with the knowledge that the incumbent law enforcement population is at increased risk of CVD, it is evident that implementing a structured physical training program targeted at maintaining cardiovascular fitness specifically could help reduce their risk of developing CVD through improving cardiovascular function and decreasing the physiological responses associated with their occupational stress. In addition, research suggests that a higher level of fitness can aid in mitigating the negative impacts of shift work (21) and by controlling BMI, reduce the potential for lower back pain (22). Changing the way in which rotation shifts are scheduled may likewise decrease fatigue and thereby reduce the negative impact of shift work on the desire to conduct physical activity. A forward or clockwise shift rotation (0900-1700 shift to a 1700-0100 shift) rather than a rearward or counter clockwise rotation (1700-0100 shift to a 0900-1700 shift) is thought to be a more natural circadian progression and it has been postulated that it takes 4 additional days to adjust to a rearward shift compared with a forward shift $(8$ versus 12 days) (30).

The $300 \mathrm{~m}$ run was the only measure that was found to be associated with both age and group, each independently (Fig 5). One possible explanation for the relationship with age may be the greater FM observed among older personnel, regardless of group. Increased levels of FM increase physiological burden, and do not contribute to force production, and therefore may in part explain the differences observed. This suggestion is inconsistent with the findings of Dawes et al., (14), who found no statistically significant differences in 300 meter run times when comparing officers with above and below average body fat percentages. However, it should be noted that the association between percentage body fat and run times in that study (14), was 
Fitness differences between police cadets and officers 20

approaching significance $(\mathrm{p}=0.06)$ and indicating poorer performance in the $300 \mathrm{~m}$ run test for officers with above average body fatness $(\mathrm{p}=0.06)$. Furthermore, though speculative, it was evident in the current study that anaerobic capacity may be affected by the decreased emphasis placed on this component of fitness upon entering the workforce, since officers exhibited lower performance on this test than cadets, independent of age effects. Anaerobic capacity is an underlying fitness characteristic for certain policing activities, such as situations requiring use of force and lasting less than 2 minutes (11). For this reason, this attribute is frequently tested and trained in the police academy setting to ensure graduating cadets are physically prepared for such tasks and to ensure they can score well on this particular test. Upon entering the work force, officers may not be required to maintain any specific fitness regimen, or to necessarily train for any specific tests (5), although this is not always the case. Therefore, the amount of time spent training anaerobic capacity is at the officer's discretion. Additionally, occupational training activities that may stimulate these physical attributes, such as defensive tactics training, may occur too infrequently to maintain this attribute at a high level. Subsequently, lower levels of performance on this test may be a function of the priority that agencies and officers place on maintaining this attribute after graduation, as well as an insufficient training stimulus to maintain this attribute.

\section{Limitations}

Two key limitations noted in this study are the transferability of findings to other law enforcement agencies and limited female officer data. Given potential differences in fitness requirements, in cadet training and potentially for incumbent officers, the fitness levels of cadets and incumbent officers, and the differences between the two, could be notably different. 
Likewise, differences in workplace tasks (e.g. foot patrol versus vehicle patrol) could influence the fitness level differences. Another potential limitation of this study is the limited number of female police officer data; both cadet and incumbent. To overcome these limitations additional studies across multiple law enforcement agencies and larger data sets of female police officer fitness levels would be of benefit.

\section{PRACTICAL APPLICATIONS}

Given the observed lower levels of incumbent officers' aerobic performance and the cardiovascular risks associated with this outcome, there would appear to be a need for more structured physical training programs for police officers, throughout their careers, in order to mitigate their risk of CVD. In addition, individual training approaches to address the observed increases in fat mass associated with aging would be of benefit to police officers, whether they be cadets or incumbent officers. Other approaches, like changes to shift rotation practices and optimized chronic back pain rehabilitation, may limit concomitant impacts of the workplace on officer fitness.

Further research is required to fully determine the underlying causes of the observed lower levels of fitness among police officers following graduation from the police academy in order to inform the development of effective physical training programs focused on maintaining an appropriate level of officer fitness for police work. In addition, future research, profiling cadet and officer fitness can be used to establish police population specific normative data and fitness classification categories. 
Fitness differences between police cadets and officers 22

\section{REFERENCES}

1. $\quad$ Åkerstedt, T. Shift work and disturbed sleep/wakefulness. Occup Med 53: 89-94, 2003.

2. Anderson, GS, Plecas, D, and Segger, T. Police officer physical ability testing-revalidating a selection criterion. Policing: An International Journal of Police Strategies \& Management 24: 8-31, 2001.

3. Arvey, RD, Landon, TE, Nutting, SM, and Maxwell, SE. Development of physical ability tests for police officers: a construct validation approach. J Appl Psychol 77: 996-1009, 1992.

4. Beck, AQ, Clasey, JL, Yates, JW, Koebke, NC, Palmer, TG, and Abel, MG. Relationship of physical fitness measures vs. occupational physical ability in campus law enforcement officers. J Strength Cond Res 29: 2340-2350, 2015.

5. Bell, M. Implementing physical fitness standards and training in law enforcement. School of Law Enforcement Supervision: Criminal Justice Institute, 2007.

6. Bonneau, J and Brown, J. Physical ability, fitness and police work. Journal of clinical forensic medicine 2:157-164, 1995.

7. Boyce, R, Jones, G, Llyod, C, and Boone, E. A longitudinal observation of police: Body composition changes over 12 years with gender and race comparisons. Journal of Exercise Physiology Online 11: 1-13, 2008.

8. Boyce, RW, Jones, GR, Schendt, KE, Lloyd, CL, and Boone, EL. Longitudinal changes in strength of police officers with gender comparisons. J Strength Cond Res 23: 2411-2418, 2009.

9. Brown, JJ, Wells, GA, Trottier, AJ, Bonneau, J, and Ferris, B. Back pain in a large Canadian police force Spine 23: 821-827, 1998. 
Fitness differences between police cadets and officers 23

10. Cocke, C, Dawes, J, and Orr, RM. The use of 2 conditioning programs and the fitness characteristics of police academy cadets. Journal of Athletic Training 51: 887-896, 2016.

11. Cooper Institute. Law Enforcement commonly asked questions: Frequently asked questions regarding fitness standards in law enforcement.

12. Dawes, J, Orr, RB, B, Conroy, R, and Pope, R. The effect of age on push-up performance amongst male law enforcement officers. Journal of Australian Strength and Conditioning 24: 23 $27,2016$.

13. Dawes, JJ, Orr, RM, Flores, RR, Lockie, RG, Kornhauser, C, and Holmes, R. A physical fitness profile of state highway patrol officers by gender and age. Annals of Occupational and Environmental Medicine 29: 16, 2017.

14. Dawes, JJ, Orr, RM, Siekaniec, CL, Vanderwoude, AA, and Pope, R. Associations between anthropometric characteristics and physical performance in male law enforcement officers: a retrospective cohort study. Annals of Occupational and Environmental Medicine 28: $1,2016$.

15. Do Lee, C, Blair, SN, and Jackson, AS. Cardiorespiratory fitness, body composition, and all-cause and cardiovascular disease mortality in men. The Amer J Clin Nutr 69: 373-380, 1999. 16. Duarte, AF, Neves, AL, Rodrigues, AV, Spier, AP, and Coertjens, M. Effects of aerobic fitness on psychological stress responses in Brazilian army soldiers. Med Sci Sports Exerc 38: S270, 2006.

17. Fekedulegn, D, Burchfiel, CM, Hartley, TA, Andrew, ME, Charles, LE, Tinney-Zara, CA, and Violanti JM. Shiftwork and sickness absence among police officers: the BCOPS study. Chronobiol Int 30: 930-941, 2013. 
Fitness differences between police cadets and officers 24

18. Franke, WD, Ramey, SL, and Shelley, MC. Relationship between cardiovascular disease morbidity, risk factors, and stress in a law enforcement cohort. J Occup Environ Med 44: 11821189, 2002.

19. Griffin, DW, Harmon, D, and Kennedy, N. Do patients with chronic low back pain have an altered level and/or pattern of physical activity compared to healthy individuals? A systematic review of the literature. Physiotherapy 98: 13-23, 2012.

20. Gyi, DE and Porter, JM. Musculoskeletal problems and driving in police officers. Occup Med. 48: 153-160, 1998.

21. Härmä, M. Ageing, physical fitness and shiftwork tolerance. Appl Ergon 27: 25-29, 1996.

22. Heuch, I, Heuch, I, Hagen, K, and Zwart, J-A. Body mass index as a risk factor for developing chronic low back pain: a follow-up in the Nord-Trøndelag Health Study. Spine 38: 133-139, 2013.

23. Hinton, B, Stierli, M, and Orr, RM. Physiological issues related to law enforcement personnel, in: NSCA's Essentials of Tactical Strength and Conditioning. B Alvar, K Sell, PA Deuster, eds.: Human Kinetics, 2017, pp 577-604.

24. Hoffman, R and Collingwood, TR. Fit for duty. Champaign:IL: Human Kinetics, 2005.

25. Jackson, AS and Pollock, ML. Practical assessment of body composition. Phys Sports Med 113: 76-90, 1985.

26. Lagestad, P and Van den Tillaar, R. A comparison of training and physical performance of police students at the start and the end of three-year police education. $J$ Strength Cond Res 28: 1394-1400, 2014. 
Fitness differences between police cadets and officers 25

27. Lagestad, P and Van Den Tillaar, R. Longitudinal changes in the physical activity patterns of police officers. International Journal of Police Science \& Management 16: 76-86, 2014.

28. Lin, C-WC, McAuley, JH, Macedo, L, Barnett, DC, Smeets, RJ, and Verbunt, JA. Relationship between physical activity and disability in low back pain: a systematic review and meta-analysis. Pain 152: 607-613, 2011.

29. Lockie, RG, Dawes, JJ, Kornhauser, CL, and Holmes, RJ. a cross-sectional and retrospective cohort analysis of the effects of age on flexibility, strength endurance, lower-body power, and aerobic fitness in law enforcement officers. J Strength Cond Res 2017. DOI:

10.1519/JSC.0000000000001937

30. Monk, TH and Folkhard, S. Making Shiftwork Tolerable. CRC Press 1992.

31. Orr, RM, and Pope, R. Optimizing the physical training of military trainees. Strength and Conditioning Journal 37: 53-59, 2015.

32. Orr, R, Knapik, J, and Pope, R. Avoiding program-induced cumulative overlead (PICO). Journal of Special Operations Medicine: A peer reviewed journal for SOF medical professionals 16: 61-64, 2016.

33. Orr, R, Pope, R, Peterson, S, Hinton, B, and Stierli, M. Leg power as an indicator for risk of injury or illness in police recruits. International Journal of Environmental Research and Public Health 13: 237-247, 2016.

34. Orr, R, Pope, R, Stierli, M, and Hinton, B. A Functional Movement Screen profile of an Australian state police force: A retrospective cohort study. BMC Musculoskeletal Disorders 17:296, 2016. doi:DOI: 10.1186/s12891-016-1146-0 
35. Orr, RM, Wilson, AF, Pope, R, and Hinton, B. Profiling the routine tasks of police officers. Journal of Australian Strength and Conditioning 24: 80, 2016.

36. Ramey, SL, Downing, NR, and Franke, WD. Milwaukee police department retirees cardiovascular disease risk and morbidity among aging law enforcement officers. Workplace Health \& Safety 57: 448-453, 2009.

37. Rhea, MR. Needs analysis and program design for police officers. Strength and Conditioning Journal 37: 30-34, 2015.

38. Sörensen, L, Smolander, J, Louhevaara, V, Korhonen, O, and Oja, P. Physical activity, fitness and body composition of Finnish police officers: a 15-year follow-up study. Occup Med 50: 3-10, 2000.

39. Violanti, JM, Fekedulegn, D, Andrew, ME, Charles, LE, Hartley, TA, Vila, B, and Burchfiel CM. Shift work and long-term injury among police officers. Scand J Work Environ Health 39: 361, 2013.

40. Wright, BR, Barbosa-Leiker, C, and Hoekstra, T. Law enforcement officer versus nonlaw enforcement officer status as a longitudinal predictor of traditional and emerging cardiovascular risk factors. J Occup Environ Med 53: 730-734, 2011. 
Fitness differences between police cadets and officers 27

Table 1. Mean results and standard deviations for key measures, by gender and group.

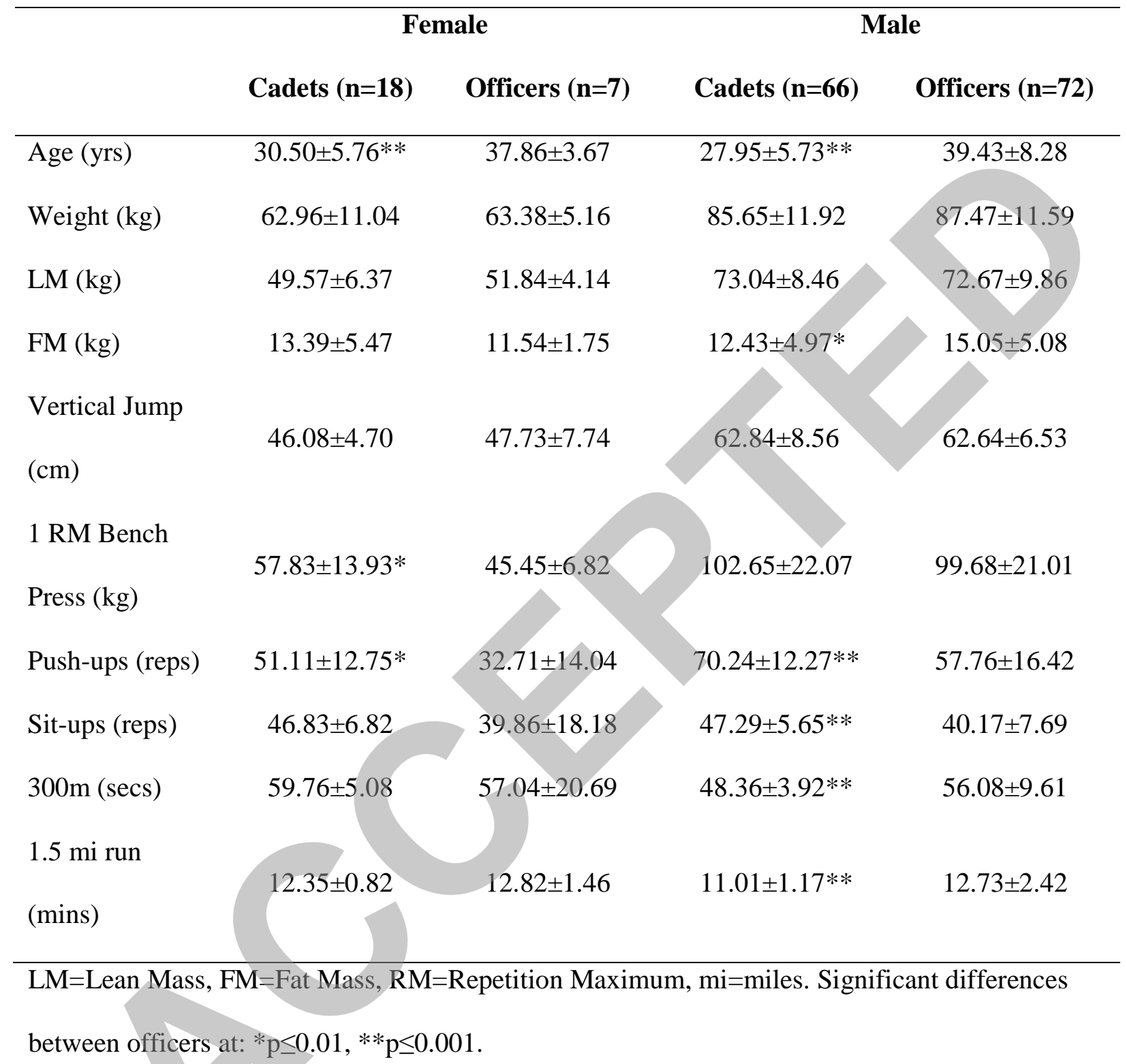


Fitness differences between police cadets and officers 28

Fig 1. Fat mass, by age bracket and group

Fig 2. Push-up results, by age bracket and group

Fig 3. Sit-up results, by age bracket and group

Fig 4. 1.5 mile run times, by age bracket and group

Fig $5.300 \mathrm{~m}$ run times, by age bracket and group 
t mass, by age bracket and group

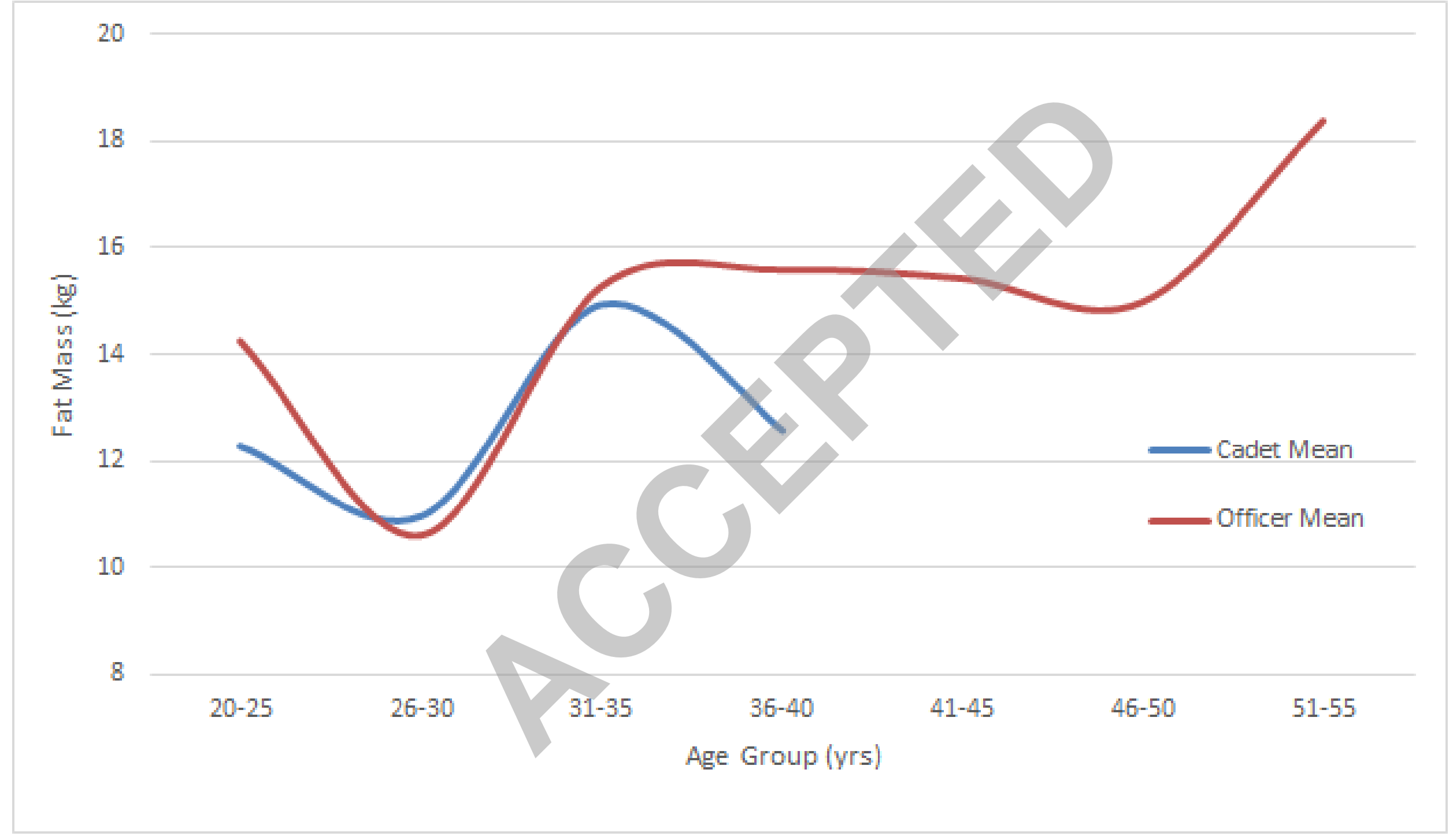




\section{Push-up results, by age bracket and group}

\section{0}

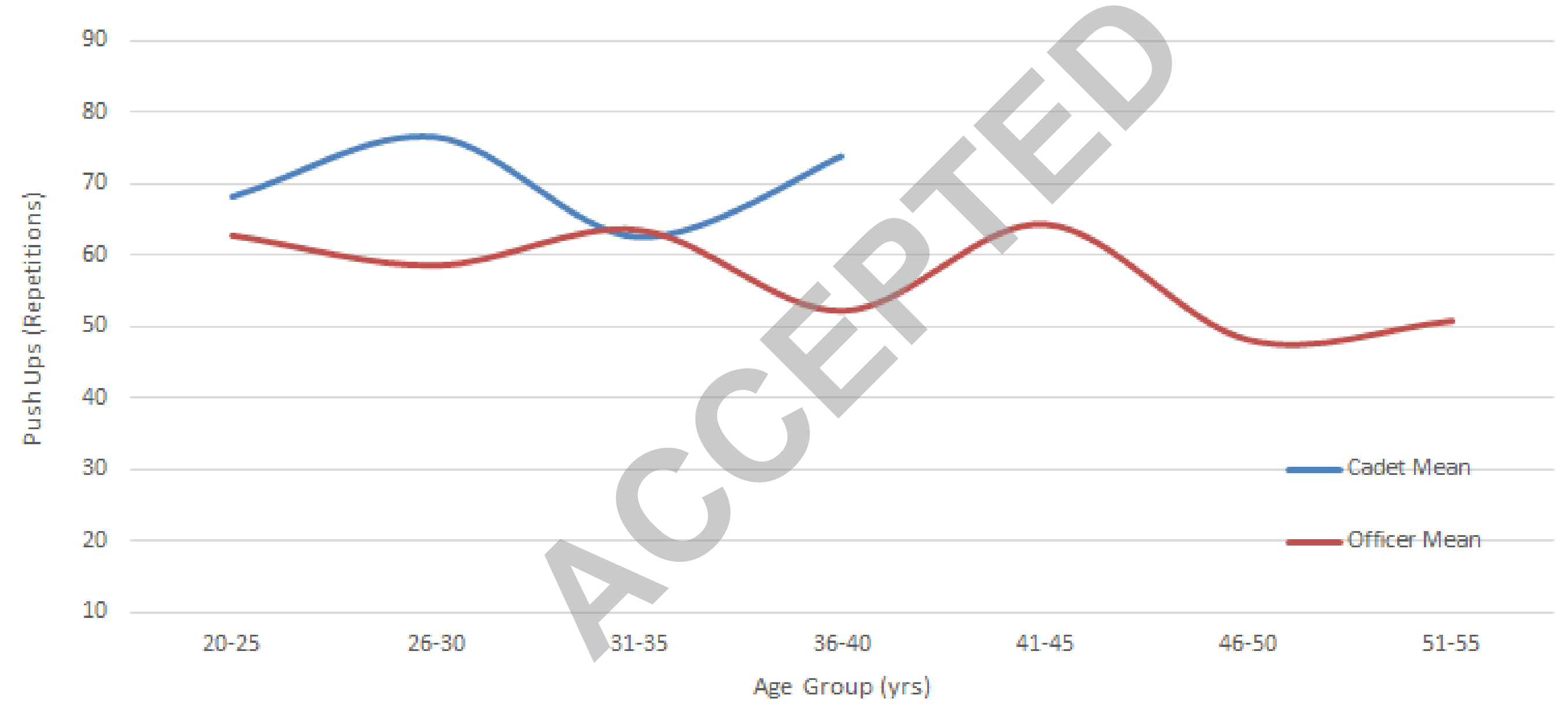




\section{it-up results, by age bracket and group}

55

50

45

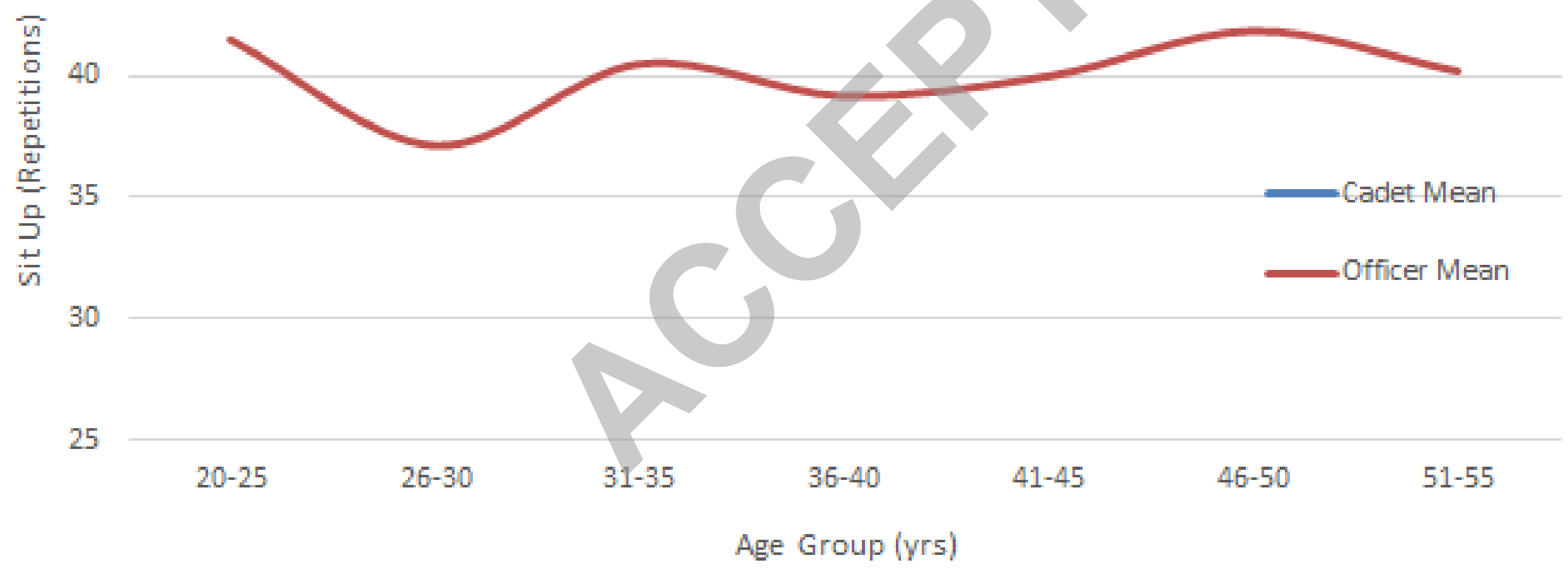




\section{5 mile run times, by age bracket and group}

16

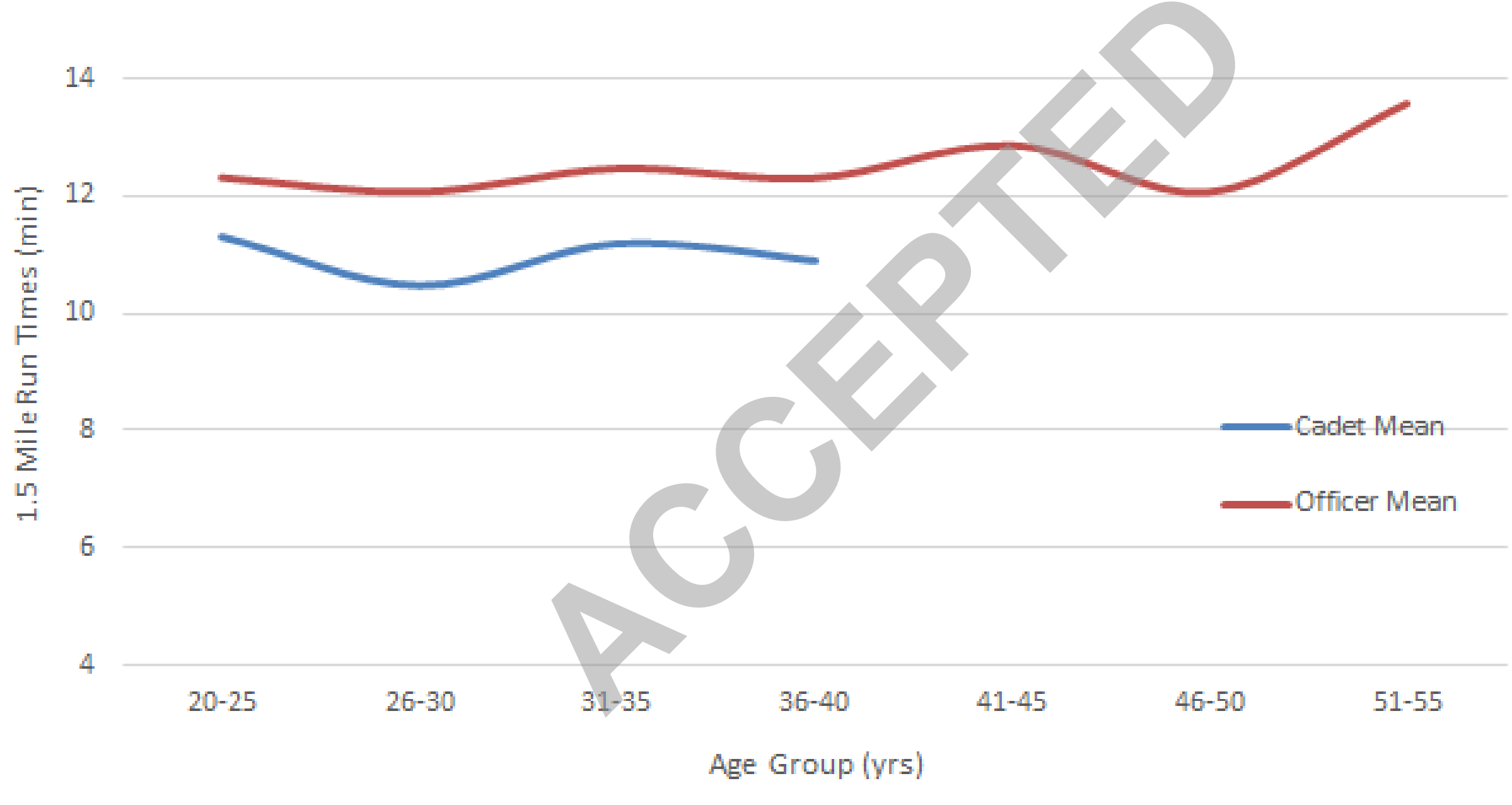




\section{$300 \mathrm{~m}$ run times, by age bracket and group}

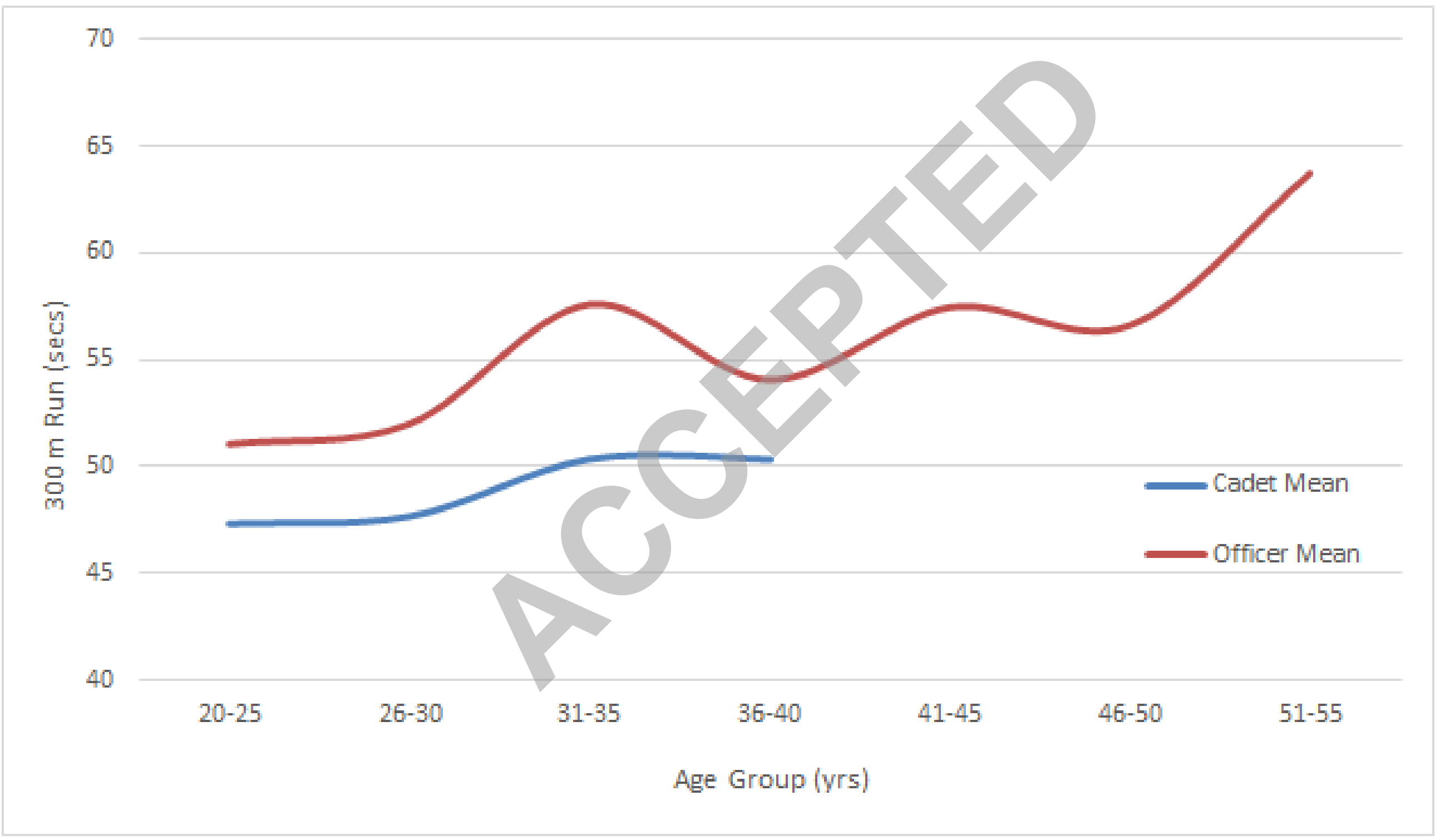

